\title{
CONCEPÇÕES, PROJETOS E EXPERIÊNCIAS DE EDUCAÇÃO INTEGRAL NO BRASIL
}

\author{
CONCEPTIONS, PROJECTS, AND EXPERIENCES OF INTEGRAL EDUCATION IN BRAZIL
}

\author{
CONCEPCIONES, PROYECTOS Y EXPERIENCIAS DE EDUCACIÓN INTEGRAL EN BRASIL
}

\author{
Marcelo Oda Yamazato ${ }^{1}$ \\ Renata Maria Moschen Nascente ${ }^{2}$
}

\begin{abstract}
Resumo: A educação integral está em pauta nos discursos políticos, acadêmicos e midiáticos no Brasil, o que torna oportuno o esforço de compreender as concepções, projetos e experiências relativas a essa forma de educação em uma perspectiva histórica. Logo, o objetivo deste ensaio é analisá-la, compreendendo as diferentes matrizes ideológicas de diversas concepções, principalmente daquelas que chegaram ao Brasil e foram concretizadas. Nas experiências brasileiras de educação integral tem havido historicamente a preponderância de fatores políticos e financeiros em detrimento dos pedagógicos e sociais, com algumas exceções, cujo foco foi a educação integral humanizadora. Confirmou-se que o tema da educação integral se mantém relevante por ser objeto de projetos em andamento em muitos municípios e estados. Foi possível ainda explicitar como suas diversas concepções remetem a diferentes visões de sociedade, para as quais deve-se ter um olhar crítico, para que se possa contribuir para uma escolarização socialmente justa e democrática.
\end{abstract}

Palavras-chave: Educação integral. Concepções. Experiências.

\begin{abstract}
Integral education is on the agenda in political, academic and media discourses in Brazil, which justifies the effort to understand concepts, projects and experiences related to it from a historical perspective. Thus, the objective of this essay is to analyze integral education, understanding the different ideological matrices of different conceptions, mainly those which arrived in Brazil and were accomplished. There has historically been a preponderance of political and financial factors to the detriment of pedagogical and social factors regarding the local experiences on integral education. The exceptions focused on comprehensive humanizing education. It was confirmed integral education remains relevant as it is the subject of ongoing projects in many cities and states. It was also possible to explain how their different conceptions refer to different views of society, for which a critical look should be taken, so that it can contribute to a socially fair and democratic schooling.
\end{abstract}

Keywords: Integral education. Conceptions. Experiences.

\footnotetext{
${ }^{1}$ Universidade Federal de São Carlos. São Carlos. São Paulo. Brasil.

${ }^{2}$ Universidade Federal de São Carlos. São Carlos. São Paulo. Brasil.
} 
Resumen: La educación integral está en los discursos políticos, académicos y mediáticos en Brasil, lo que hace el esfuerzo de comprender las concepciones, proyectos y experiencias relacionadas con esta forma de educación en una perspectiva histórica. El objetivo de este ensayo es analizarlo, entendiendo las diferentes matrices ideológicas de diferentes concepciones, principalmente las que Ilegaron a Brasil y se realizaron. En las experiencias brasileñas, históricamente ha habido una preponderancia de factores políticos y financieros en detrimento de los factores pedagógicos y sociales, con algunas excepciones, cuyo enfoque ha estado en la educación integral humanizadora. Se confirmó que el tema sigue siendo relevante ya que es objeto de proyectos en curso en muchos municipios y estados. También fue posible explicar cómo sus diferentes concepciones se refieren a diferentes visiones de la sociedad, para lo cual se debe tener un ojo crítico, para que se pueda contribuir a una escolarización socialmente justa y democrática.

Palabras clave: Educación integral. Concepciones. Experiencias.

\section{INTRODUÇÃO}

Em tempos de democracia ameaçada por políticas públicas ao mesmo tempo neoliberais e neoconservadoras, adjetivadas como eficientes, eficazes e desburocratizantes (BARROSO, 2005), a educação integral tem permeado tanto os discursos dos políticos, como dos denominados 'especialistas em educação' do terceiro setor, e, consequentemente, da mídia em geral, como uma das panaceias para a salvação da educação no país. Por meio de processos de privatização da educação pública disfarçados, tais como escolas militares, escolas charter, adoção de materiais didáticos, técnicas de ensino e de gestão colocadas a pronta entrega no mercado, o Estado vem tentando diminuir o seu papel de provedor da educação para assumir o de regulador, mormente, por meio das avaliações externas e de diversos outros processos de responsabilização.

Destarte, a educação integral seria a resposta de um Estado mínimo, quase mercado, à população, na perspectiva da livre escolha e da meritocracia. Isto é, esvazia-se o direito subjetivo e universal à educação básica, garantido pela Constituição Federal (BRASIL, 1988), para que cada família, de acordo com o bairro em que vive, renda e aspirações sociais, 'escolha' a escola para seus filhos e filhas. Além disso, manter crianças e adolescentes o maior tempo possível nas escolas é uma solução compartilhada pelos setores de segurança pública, educação, saúde, e, aparentemente, pelas próprias famílias, para protegê-los(as) da criminalidade e do tráfico de drogas, possibilitando que os pais trabalhem sabendo que seus filhos estão em segurança nas escolas.

Paro et al (1988) já defendiam a ideia de que a oferta de educação escolar em tempo integral seria fundamental para que crianças e jovens das classes sociais mais baixas pudessem apropriar-se do conhecimento científico, tecnológico e cultural, produzido historicamente. Essa apropriação 
propiciaria uma formação humana para a autonomia e participação democrática (FREIRE, 2002), voltada ao exercício da cidadania.

Nesse sentido, Bernardo (2020) esclarece que educação integral e educação em tempo integral não são a mesma coisa, apesar de reconhecê-las como concepções afinadas com projetos de escolas que se distinguem das tradicionais, com base na igualdade entre as pessoas e na valorização de saberes para além dos conteúdos formais.

[...] ampliar o tempo dos discentes sob responsabilidade da escola em busca por maior equidade e qualidade na educação é ir além do que está posto. Quando tratamos da ampliação da jornada escolar, é importante considerar que essa educação deve propiciar múltiplas oportunidades de aprendizagem articuladas com o projeto político-pedagógico da escola e, assim, proporcionar ao estudante uma educação de fato integral e de qualidade (BERNARDO, 2020, p. 91).

Tendo distinguido conceitualmente a educação integral da educação em tempo integral, apesar de reconhecer suas imbricações, esclarece-se que o objeto deste ensaio é a primeira. 0 objetivo é analisar a educação integral sob a perspectiva de seu desenvolvimento e contexto históricos, tentando compreender as diferentes matrizes ideológicas de suas diversas concepções, principalmente daquelas que deram origem a projetos e experiências educacionais concretas no Brasil. Dessa maneira será possível responder à questão que levou à sua elaboração, qual seja: quais são as concepções do que seria e como se viabilizaria a educação básica integral em nosso país? Nossa tese é a de que essas concepções vêm sendo elaboradas e reelaboradas historicamente, com base em diferentes projetos de sociedade, com significativa influência de fatores econômicos e políticos.

O artigo está organizado em cinco seções. A primeira é esta introdução; a segunda refere-se às concepções de educação integral em sentido amplo; a terceira se constitui em uma análise das concepções de educação integral que chegaram ao Brasil tendo sido (re) elaboradas por educadores brasileiros. Na quarta são discutidos projetos e experiências de educação integral em nosso país. Na quinta e última, apresentamos nossas considerações finais. 


\section{CONCEPÇÕES DE EDUCAÇÃO INTEGRAL}

A educação como processo de humanização tem papel central na organização da convivência nas sociedades. A ideia da formação integral do ser humano faz parte desse constructo. Ao se compreender o homem como um ser multidimensional, a educação se coloca num horizonte amplo para o desenvolvimento humano, tal que passa a responder a diversas expectativas do próprio sujeito. Nesse sentido, a integralidade do homem não é um conceito definitivo ou absoluto, de modo que não pode ser compreendido de forma neutra ou alheia a um projeto de sociedade.

A educação integral, ao buscar atingir as potencialidades de cada indivíduo, traz consigo conjuntos de práticas sociais e pedagógicas que pressupõem uma certa concepção de ser humano. Entretanto, o que, quando e quem define quais as qualidades e atributos de um sujeito integral, são indicativos a serem observados para se interpretar as conotações políticas e sociais envolvidas nesse conceito.

A ideia de educação integral do ser humano é uma discussão antiga, remetendo em suas origens à Grécia Antiga, onde foram identificados os primeiros registros da história da educação com algum sentido social. A formação do homem grego em sua totalidade chamava-se Paideia. Os gregos possuíam uma concepção ampliada de educação, tal que "a ideia de educação representava todo o sentido do esforço humano, a justificação última da comunidade e individualidade humana" (DIAS, 2015, p. 40).

Na Grécia Antiga, a educação integral era para poucos, restrita à elite econômica e intelectual, enquanto as demais camadas eram instruídas nos ofícios, sendo predominantemente destinada a meninos. Essa educação elitizada valorizava as atividades intelectuais - particularmente as artes e a filosofia - o que pode ser entendido como um indicativo de ligação entre educação, valores e convivência humana. A arte de governar a polis, a política, colocava a ética como eixo norteador e intrínseca à formação humana (COELHO, 2009).

Ainda segundo Coelho (2009), a formação humana deixou de ser um tema de debate aprofundado por séculos após os gregos. A materialização da educação formal em instituições públicas, como entendida atualmente, viria a acontecer no século XVIII com a Revolução Francesa e a constituição da escola pública. A Modernidade e o movimento iluminista desvinculam o 
cristianismo da produção de conhecimento, o que faz com que o primeiro perdesse hegemonia como metanarrativa do mundo ocidental.

Os ideais franceses de liberdade, igualdade e fraternidade e a crescente valorização da razão e do conhecimento se estabeleceram em diversos âmbitos sociais, inclusive na educação. Rompendo com o tradicional ensino ministrado pela Igreja Católica, foi instituída a escola primária pública, como um dever do Estado, única, laica, gratuita e universalizada. Sob os preceitos republicanos e jacobinos franceses, buscava-se uma educação nacional na qual a formação do homem completo significaria abranger as dimensões física, moral e intelectual de cada aluno (COELHO, 2009). Naquele contexto a educação integral tinha o objetivo de "[...] formar o cidadão republicano, disciplinado, patriota, cívico, pronto para a luta e para morrer por seu país e pela defesa dos ideais republicanos e revolucionários" (DIAS, 2015, P. 43).

A perspectiva de uma escola que oferecesse educação integral foi destaque no pensamento de dois importantes teóricos da educação daquele período: o alemão Friedrich Froebel (1782-1852) e o suíço Johann Heinrich Pestalozzi (1746-1827). O primeiro é considerado o fundador dos jardinsde-infância e defendia uma educação com autoconhecimento e liberdade. O segundo compreendia a educação de um ponto de vista social, de forma que:

[...] a postura pestalozziana, portanto abrangia conceitos de uma educação integral, pois falava da educação intelectual, técnica e moral; ressaltando a criança em relação com a natureza e cultura, alertando assim para a revalorização social desse aluno [...] O conceito de escola popular ganhou, com Pestalozzi, um novo sentido [...] deixava de ser uma escola de simples instrução ao apresentar singular empenho no problema da formação humana (CAIUBY, 2015, p. 27).

Além da Revolução Francesa, o século XVIII também foi marcado pela Revolução Industrial. Se, de um lado, construíam-se os ideais iluministas e republicanos sobre a formação plena e livre do homem, do outro, a urbanização e a industrialização das sociedades cresciam de maneira veloz e desorganizada. Nesse processo, evidenciaram-se as desigualdades sociais e as precárias condições de vida, acompanhada pela crescente alienação dos trabalhadores e dos processos produtivos. Assim, a escola começou a exercer um importante papel disciplinador na sociedade que surgia. Segundo Mariana (2011), à semelhança do ensino religioso que foi usado como base pedagógica na manutenção das estruturas de poder das monarquias, a escola moderna passou a assumir essa função para a emergente classe burguesa. Além do mínimo conteúdo técnico necessário para operações manuais, essa escola adotava e ensinava a disciplina do trabalho industrial. 
Em contrapartida, naquele período, ainda de acordo com Mariana (2011), a educação integral significou uma possibilidade de resistência da nascente classe operária do século XIX. Os conceitos da formação do homem em sua integralidade - a conjugação das capacidades físicas, intelectuais e morais -, antagonizavam as novas formas de dominação social que surgiram e se consolidaram durante a Revolução Industrial.

Nesse ambiente, ao mesmo tempo alienante e emancipador do século XIX, destacaram-se as teorias educacionais dos anarquistas. Com base em princípios libertários, lutavam por uma educação que unisse trabalho manual e intelectual, de modo a formar o homem em seus diferentes aspectos: mental, moral, político e artístico. Dessa maneira, segundo Coelho (2009), estabeleceram as bases para uma educação igualitária, voltada à autonomia. Esses princípios são reconhecidos por Dias (2015, p. 48), para quem a proposta pedagógica anarquista: “[...] é composta por dois eixos fundamentais, que se entrelaçam: a escola deve educar integralmente o homem e educar para a liberdade. Somente um homem completo em sua humanidade pode conquistar socialmente sua liberdade". Nesse sentido, o autor explica que os burgueses recebiam uma educação superior à das massas operárias, tal que os anarquistas demandavam formação integral para o povo para que as massas pudessem se libertar do julgo burguês. Ademais, educação integral nos moldes anarquistas possuía caráter emancipador e político. Gallo (2012, p. 175), sintetiza essa concepção:

Como o socialismo libertário vê no homem alienado um dos pilares da sociedade de exploração, a educação deve ser um instrumento para a superação dessa alienação. A educação integral é o caminho para esta superação, e um passo na transformação desta sociedade, pois pretende educar o homem sem separar o trabalho manual do trabalho intelectual, pretende desenvolver as faculdades intelectuais, mas também desenvolver as faculdades físicas, harmonizando-as. E, além disso, pretende ainda trabalhar uma educação moral, uma formação para a vida social, uma educação para a vivência da liberdade individual em meio à liberdade de todos, da liberdade social (GALLO, 2012, p. 175).

As ideias relativas à educação integral adquiriram maior relevância no Brasil ao final do século XIX, no conjunto de influências dos ideais republicanos e de modernização da sociedade. Naquele contexto, a concepção anarquista de educação marcou a educação integral por seu caráter político e também serviu de base para propostas alternativas de ensino. No início do século XX, em particular a partir da década de 1930, a educação integral assumiu uma posição de maior destaque no debate político e educacional no país. Esse cenário pode ser entendido pela coexistência e 
competição de/entre concepções educativas diversas na sociedade brasileira, cada uma representando diferentes projetos de sociedade.

\section{CONCEPÇÕES DE EDUCAÇÃO INTEGRAL NO BRASIL}

No final do século XIX, quando o Brasil deixou de ser um império para tornar-se uma república, a sociedade brasileira passou por diversas mudanças em sua estrutura econômica e social; de uma base rural, agrária e escravocrata, para uma outra, urbana e comercial. Em busca da modernização do país, a educação e a instituição escolar destacaram-se como pilares fundamentais para seu desenvolvimento. Segundo Bonato, Coelho e Menezes (2011), na década de 1870, ainda durante o império, profissionais com níveis mais altos de instrução - médicos, engenheiros, políticos, entre outros -, denunciavam deficiências na educação e na escola. Dessa forma, alguns membros da elite intelectual brasileira, numa tentativa de integrar-se ao movimento internacional de modernização e desenvolvimento liberal, realizaram, a partir de 1873, "conferências pedagógicas, onde temas como as inovações do mundo moderno e o fracasso do método mútuo ${ }^{3}$, moral e higiene, eram discutidos" (BONATO; COELHO; MENEZES, 2011, p. 279).

Naquele momento histórico, destacaram-se Leôncio de Carvalho e Rui Barbosa. Introduzindo as ideias liberais na sociedade e educação brasileira, Leôncio de Carvalho, por meio do Decreto de 19 de abril de 1879, reformou a instrução pública primária e secundária no Município da Corte e o ensino superior em todo o Império. De cunho liberal, instituiu a liberdade de ensino e a liberdade de frequência. Essas medidas causaram muita polêmica, porque possibilitavam "que todos os que se considerassem capacitados para ensinar poderiam fazê-lo, independentemente de serem professores, expondo suas ideias e adotando os métodos que melhor lhes conviessem" (BONATO; COELHO; MENEZES, 2011, p. 279). Em um período em que o Estado era pouco presente na educação, tal medida garantiu espaço para iniciativas privadas nesse campo, especialmente para as escolas confessionais. Os autores destacam ainda outros aspectos importantes contemplados nessa reforma: garantia de instrução primária e gratuita para todos os cidadãos, a coeducação dos

\footnotetext{
${ }^{3}$ Criado por Joseph Lancaster, com base no ensino oral da repetição e memorização e na utilização de alunos monitores, esse método buscava suprir a necessidade de ensinar uma massa de alunos em pouco tempo com poucos recursos.
} 
sexos, frequência obrigatória para jovens de sete a 14 anos, multas para pais e/ou tutores que deixassem de matricular os jovens dessa faixa etária, entre outros.

[...] a análise da reforma Leôncio de Carvalho nos permite inferir que há uma associação entre educação integral e ampliação do tempo escola, no caso, 6 (seis) horas diárias para os jovens com dez anos ou mais. Afora isto, ao determinar, nos diferentes distritos do mesmo município, a criação de pequenas bibliotecas e museus escolares (art. $7^{\circ}$ ), embora de forma embrionária, traz para a reflexão aspectos pertinentes a ampliação não só do tempo, mas, também, dos espaços educacionais, enquanto aspectos relacionados (porém, não-necessários) à configuração de uma educação integral à época (BONATO; COELHO; MENEZES (2011, p. 280).

Essa reforma deu origem aos Pareceres/Projetos de Rui Barbosa intitulados Reforma do Ensino Secundário e Superior (1882) e Reforma do Ensino Primário e várias Instituições Complementares da Instrução Pública (1883). Nesses documentos, Rui Barbosa defendia a ampliação do programa escolar e justificava o ato pelo "[...] princípio da educação integral, princípio instituído sob a égide da mesma trindade pedagógica defendida por médicos higienistas: educação física, intelectual e moral" (BONATO; COELHO; MENEZES, 2011, p. 281).

[...] para Rui Barbosa, educação integral significa ampliação da formação do aluno no ensino primário "numa recapitulação tão completa quanto ser possa, do progresso que a humanidade tem efetuado por entre o curso dos séculos". Significa assim trabalhar, na escola, "da maneira mais completa possível, todas as suas faculdades físicas e intelectuais"; em outras palavras, significa ensinar as disciplinas das ciências físicas e naturais, a língua materna, a matemática, a história e a geografia, mais a educação física, a música, o desenho, o canto, os "rudimentos de economia política", cultura moral, cultura cívica ou seja, todas as que [...] constituem as habilidades físicas, cognitivas e estéticas que completam, no sujeito, o seu SER humano (BONATO; COELHO; MENEZES 2011, p.283).

Posteriormente, no início do século XX, no Brasil, passaram a coexistir diferentes movimentos debatendo a educação, a escola e sua função na sociedade, como pilar na integração nacional, de forma que "o modelo republicano reconhecia na escola o instrumento a serviço da formação do homem, capaz de colaborar para o desenvolvimento da sociedade" (BALDANÇA; MIGUEL, 2015, p. 5207). A educação foi supervalorizada como possibilidade de resolução de problemas sociais e econômicos do país. Nessa perspectiva, educação integral foi apresentada em propostas de matrizes ideológicas e teorias metodológicas diversas, destacando-se as concepções socialistas (representadas pelo pensamento anarquista), conservadoras (a católica e a integralista) e as liberais (escolanovismo). 
Liberais como Anísio Teixeira, por exemplo, defendiam uma educação o mais completa possível, consubstanciada no contraturno escola [..] Já os socialistas, ao propor a educação integral, faziam-na pensando em várias atividades esportivas, artísticas e cognitivas acontecendo mescladas, ao longo do dia [...]. E o que dizer do pensar-agir de conservadores, como os integralistas, que advogavam uma educação integral para o homem integral, ou ainda, como os católicos, que fundaram instituições escolares em cujos espaços essas atividades também aconteciam, por vezes, ao longo do dia? Esses são apenas alguns exemplos de como a abordagem político-filosófica entende educação integral (COELHO; MARQUES; BRANCO, 2014, p. 357).

Segundo Mariana (2011), o pensamento anarquista no Brasil influenciou a abertura da Universidade Popular durante o ano de 1904, na cidade do Rio de Janeiro, que oferecia diversos cursos, tais como filosofia, mecânica, aritmética, administração, entre outros. Essa experiência foi marcada pelo movimento de trabalhadores "não apenas através da onda de greves [...], mas também pela atuação de intelectuais, artistas e estudantes que [...] propunham a organização de centros de estudos sociais" (p. 06). Além da Universidade Popular, o autor também se refere às Escolas Modernas como parte do movimento pela educação integral de caráter anarquista. Para além dessas experiências, a influência dos ideais libertários se evidenciava na concepção de educação de cunho político:

Ao procurar constituir a pedagogia da pergunta; a solidariedade, nas tarefas manuais; o espírito coletivo, através das atividades esportivas e jogos, constituíase o cidadão emancipado, questionador, e construtor de uma história coletiva (COELHO, 2004, p. 06).

Em 1932, o documento Manifesto dos Pioneiros da Educação Nova marcou a educação brasileira e uma geração de intelectuais que visava a modernização do país tomando a educação como chave para o desenvolvimento. O movimento era caracterizado pela Pedagogia Nova, ou escolanovismo, que se diferenciava das pedagogias 'tradicionais'. As finalidades da educação não se restringiriam à sala de aula, mas para toda uma vida em sociedade. A educação seria pública, única, laica, gratuita e obrigatória, sendo concebida como um direito de todos. De ideário liberal, ressaltam-se aspectos como "igualdade de oportunidades e democratização da sociedade via escola; a noção de escola ativa; [...] distribuição hierárquica dos jovens no mercado de trabalho" (DIAS, 2015, p. 56). Para os liberais, a educação integral era fundamental para uma sociedade democrática, pois a democracia só se desenvolveria "a partir de indivíduos intencionalmente formados para a cooperação e a participação" (CAVALIERE, 2010a, p.249). 
Anísio Teixeira foi um dos principais nomes do escolanovismo, tendo sido fortemente influenciado pelo pensamento e concepções pedagógicas de John Dewey, para quem "a escola teria uma natureza moral e social, e poderia funcionar como uma espécie de 'comunidade em miniatura' a participar da recriação permanente da sociedade" (CAVALIERE, 2009, p. 60). Criticando o modelo convencional de ensino, propunha uma escola "em que a própria vida estivesse presente dentro dela, e não apenas a chamada preparação para a vida" (p. 60); logo,

[...] tinha como referência a concepção da educação como um processo de reconstrução ou reorganização das experiências, particularmente aquelas que criam significados, isto é, que são conhecimento, e aumentam a capacidade de conduzir o curso das experiências subseqüentes (Dewey, 1959). Dessa forma, para ele, a educação não abriria mão de um sentido intencional, de um projeto, mas o refaria permanentemente, à medida que o experimentasse (CAVALIERE, 2009, p.60).

Nessa linha de pensamento, Anísio Teixeira (1962) também criticava o modelo de ensino tradicional e propunha uma educação que ultrapassasse a instrução escolar, na qual a escola, além de instruir, fizesse os papeis de casa e família. Deveria oferecer à criança oportunidades completas de vida, que incluíssem atividades de estudo, trabalho, vida social, recreação e jogos. Para isso, seriam necessários novos currículos, programas e professores. Para o autor, "a experiência tradicional da escola é a de manter a sociedade existente" (p. 3), tal que entendia que a educação integral como uma "escola destinada não sòmente a reproduzir a comunidade humana, mas de erguê-la a nível superior ao existente no país". Desse modo, essa educação deveria se basear em “atividades intelectuais, artísticas, profissionais, físicas e de saúde, além daquelas de cunho éticofilosófico (formação de hábitos e atitudes, cultivo de aspirações)" (COELHO, 2009, p. 89). Além disso, deve-se ressaltar que Teixeira (1962), alinhado ao pensamento liberal, concebia a formação completa do aluno como uma forma de alavancar o progresso do país.

A Igreja Católica se opunha ao escolanovismo e, por meio de suas escolas, trabalhava uma educação integral baseada em atividades físicas, intelectuais e ético-religiosas. Segundo Dias (2015), a educação era entendida como forma de ordenar as faculdades humanas e conduzir o homem ao seu supremo fim (grifo do autor). A educação integral visava à aproximação com Deus, que seria a integralidade da felicidade. Além disso, um dos principais pontos de suas ações era combater a laicização do ensino. "Para os católicos, tanto a laicidade quanto o monopólio estatal do ensino atentavam contra a ordem natural e divina" (p.59). 
Outro movimento importante para a educação escolar nesse período foi o integralismo. A fundação da Ação Integralista Brasileira em 1932 fortaleceu a direita política conservadora. Para o movimento integralista, a educação integral seria baseada na espiritualidade, no nacionalismo cívico e na disciplina. Segundo Coelho (2005), a educação integral para formar o homem integral era constante no discurso integralista, de forma que a escola ideal seria fundamentada na tríade Deus, Pátria e Família, constituindo-se em um prolongamento do lar familiar. Nesse sentido, para os integralistas, "a escola deve ser um prolongamento ou uma expressão da vida familiar, pelas atividades comuns a uma e outra, tais as formas de cooperação, a autoridade, a disciplina, a obediência e o respeito mútuo" (p.84). Além disso, Dias (2015, p. 60) afirma que "esse ideário de Educação Integral ultraconservador pretendia o disciplinamento do cidadão, o controle, a preparação para o mundo do trabalho e conservação da estrutura social vigente".

Como foi possível observar, a educação integral foi concebida de diferentes formas ao longo da história, mais especificamente, no Brasil desde o início do século passado. Assim, atualmente, quando ela tem se consolidado nos discursos político, econômico e midiático, não há como escapar da complexidade do que se pode entender como educação integral, e, os possíveis entendimentos não podem ser analisados de forma neutra ou sem uma reflexão crítica sobre seu contexto históricosocial. A educação integral é perspectivada ante um entendimento de sociedade, de forma que experiências realizadas no país nos ajudam a compreender tal horizonte. Dentre as concepções estudadas nesta seção, destacou-se a influência que a do educador Anísio Teixeira teve no entendimento sobre educação integral no Brasil. Suas proposições foram concretizadas no Centro Educacional Carneiro Ribeiro e servem de inspiração para diversas outras iniciativas de educação integral no país até hoje. Tais projetos são abordados na próxima seção.

\section{PROJETOS E EXPERIÊNCIAS DE EDUCAÇÃO INTEGRAL NO BRASIL}

As experiências de implantação políticas e tentativas de se implementar uma educação integral pública no país têm sido diversas, tal que, nesta seção, o foco recai sobre duas que marcaram a educação brasileira e a concepção de educação integral: o Centro Educacional Carneiro Ribeiro (CECR) concebido por Anísio Teixeira e os Centros Integrados de Educação Pública (CIEP) de Darcy Ribeiro. 
Anísio Teixeira (1962) defendia uma formação completa na escola para viabilizar o progresso e o desenvolvimento do país, em detrimento do modelo tradicional de instrução vigente na primeira metade do século XX. Igualmente, advogava por uma educação integral pela qual a escola pudesse oferecer amplas oportunidades de vida aos estudantes. Portanto, tratava-se de expandir culturalmente a instrução primária "[...] até então caracterizada praticamente como escola alfabetizadora - para que a população, sobretudo das áreas mais pobres, se integrasse no contexto de uma sociedade moderna" (NUNES, 2009, p.123).

Com esse objetivo, Anísio Teixeira criou o Centro Educacional Carneiro Ribeiro, no bairro popular da Liberdade, em Salvador. Era um conjunto de quatro escolas-classe de ensino primário para 1000 alunos cada, divididos em dois períodos, nas quais se desenvolviam as atividades normais e/ou convencionais das demais escolas, voltadas às ciências físicas e sociais, à leitura, à escrita e à aritmética. Além disso, havia uma escola-parque com sete pavilhões, que era destinada às atividades complementares no contraturno das aulas tradicionais, tais como trabalhos manuais, artes industriais, educação artística, educação física e atividades socializantes. Cada professor era responsável por até 20 alunos, tendo sido recrutados na capital e no interior da Bahia e passado por cursos de aperfeiçoamento. Fiel à ideia de que a escola deveria ser uma 'comunidade em miniatura', o complexo, em sua área de 42 mil metros quadrados, era composto por doze salas de aula em cada escola-classe, gabinetes médico e dentário, um ginásio de esportes, pavilhões de trabalho e de atividades sociais, um teatro com 560 lugares, uma biblioteca, um restaurante, além de lavanderia, padaria e banco.

A filosofia da escola visa a oferecer à criança um retrato da vida em sociedade, com as suas atividades diversificadas e o seu ritmo de "preparação" e "execução", dando-lhe as experiências de estudo e de ação responsáveis. Se na escola-classe predomina o sentido preparatório da escola, na escola-parque [...] predomina o sentido de atividade completa, com as suas fases de preparo e de consumação, devendo o aluno exercer em sua totalidade o senso de responsabilidade e ação prática (TEIXEIRA, 1962, p.02).

O Centro Educacional Carneiro Ribeiro foi inaugurado em 1950, mas somente em 1962 é que a maioria dos seus espaços - como a biblioteca, o teatro e o pavilhão de atividades sociais da 'escolaparque' - foram concluídos. Segundo Cavaliere (2010b, p. 257), o projeto recebeu críticas “cuja tônica era a denúncia do estado precário em que se encontravam as demais escolas do Estado". Além disso, na ditadura militar em 1964, Anísio Teixeira foi afastado da vida política, de forma que “após o seu afastamento, os projetos nos quais estavam inseridas as 'escolas-parque' [...] passaram 
a sofrer modificações de diversas naturezas, além de deformações e perseguições" (MARTINS, 2006, p. 153). Segundo a autora, ao longo dos anos de 1970 a 1990, houve iniciativas para restauração do centro, uma vez que as instalações físicas da escola-parque se encontravam em situação de abandono e depredação. Com algumas modificações para atender novas demandas, o Centro Educacional Carneiro Ribeiro foi (re)inaugurado em 28 de fevereiro de 2002 depois de cinco anos totalmente desativado.

Já na década de 1980, Darcy Ribeiro projetou e implantou os Centros Integrados de Educação Pública - CIEPs - no Estado do Rio de Janeiro. Com prédios projetados por Oscar Niemeyer, os CIEPs localizavam-se preferencialmente em regiões com população carente e possuíam:

[...] três blocos. No bloco principal, com três andares [...] as salas de aula, um centro médico, a cozinha e o refeitório, além das áreas de apoio e de recreação. No segundo bloco, fica o ginásio coberto, com sua quadra de vôlei/basquete/futebol de salão, arquibancada e vestiários. Esse ginásio é chamado de Salão Polivalente, porque também é utilizado para apresentações teatrais, shows de música, festas etc. No terceiro bloco, de forma octogonal, fica a biblioteca e, sobre ela, as moradias para alunos-residentes (RIBEIRO, 1986 apud COELHO, 2009, p.92).

Segundo Monteiro (2009, p. 38), o projeto curricular dos CIEPs tinha a "cultura como eixo articulador das atividades pedagógicas" de forma que todas as atividades realizadas eram entendidas como educativas. Assim, a escola se apresentava como "pólo de dinamização cultural [...] com abertura para receber e incorporar saberes próprios à comunidade" (p.38). As bases teóricas desse projeto, de acordo com Silva (2009), se assentavam na pedagogia da Escola Nova de John Dewey, na teoria da violência simbólica de Bourdieu e Passeron e na teoria de Paulo Freire "[...] na qual "na qual o processo de aprendizagem da leitura e da escrita está sempre ligado ao exercício da leitura crítica do mundo" (p.19).

Não à toa que os CIEPs, inspirados pela experiência de Anísio Teixeira, possuíam semelhanças com o CECR. Ambos buscavam ser mais do que somente escolas, eram centros de educação que proporcionavam oportunidades de colocar em pé de igualdade as condições sociais e culturais das diversas e desiguais classes sociais; constituindo-se como 'comunidades em miniatura'. Além disso, ofereciam atividades variadas além das tradicionais da educação formal. Jacomeli, Barão e Gonçalves (2017) explicam que ambos buscaram criar uma demanda na população por um outro tipo de escola, de forma que as próprias forças sociais impulsionariam sua reprodução. Apesar da semelhança entre os dois projetos, há distinções a serem compreendidas. 
Darcy Ribeiro ousa massificar um experimento - um contra-senso nos próprios termos. Neste ponto, me parece, reside a maior distinção entre ele e Anísio Teixeira: um conferindo ao seu projeto um cunho político-sociológico e o outro, Anísio, defendendo gradualmente o modelo pedagógico. [...] Mas, uma vitória esse esforço monumental alcançou: o Ciep tornou-se referência para qualquer discussão sobre escola em tempo integral, confundindo-se completamente com o seu ideário (BOMENY, 2009, P.117).

Os projetos de educação integral de Anísio Teixeira e de Darcy Ribeiro foram referências para diversos outros elaborados e colocados em prática a partir da década de 1990. Alguns foram bastante expressivos, tanto em número de crianças e jovens atendidos como em longevidade. Um deles, os Centros Ligados ao Apoio da Criança - CIACs, posteriormente Centros de Atenção Integral ao Apoio da Criança e ao Adolescente - CAICs, foram implementados durante o governo Fernando Collor, tendo como foco prioritário mais a atenção à criança do que a educação integral (FIGUEIREDO, 2014). Posteriormente, os CAICs foram implantados em todo Brasil, nos âmbitos dos sistemas municipais de educação, muitos deles estando ainda em pleno funcionamento.

Entre os anos de 1986 e 1993, foi implantado no estado de São Paulo o Programa de Formação Integral da Criança - Profic (GIOVANNI; SOUZA, 1999), que teve o objetivo de "estender o tempo de permanência das crianças pobres na escola e expandir as condições para seu melhor desempenho na aprendizagem" (p. 70), tendo se concretizado por meio de parcerias entre estado, municípios e instituições filantrópicas. O programa era de adesão voluntária tanto de escolas públicas como privadas. Destacou-se nele a função protetiva mais do que a educativa, ou seja, "a criança estaria protegida da violência, do desamparo circunstancial, da doença, da fome e da pobreza" (p.74).

Durante os governos Lula e Dilma, o programa Mais Educação caracterizou-se como uma política pública de largo espectro, envolvendo financiamento (SILVA, 2015) e orientação do governo federal em parceria com escolas estaduais e municipais que o aderissem. Tratou-se mais de uma indução à educação integral, do que uma iniciativa de oferta desse tipo de educação, pois constituíase de atividades a serem realizadas por estudantes universitários bolsistas nas escolas no contraturno das aulas do ensino regular. Dessa forma, o programa pode ser entendido como uma complementação da educação básica ofertada por estados e municípios. 
Destacam-se ainda no escopo das experiências de educação integral os Centros Educacionais Unificados - CEUs, implantados no município de São Paulo a partir de 2003, durante a administração da prefeita Marta Suplicy, que se referenciavam fortemente na educação popular, tendo a promoção da cidadania na perspectiva da participação como objetivo fundamental, incrementada pelo atendimento integral não só aos estudantes, mas às comunidades de entorno (FIGLIOLINO, 2014). A ideia geradora do projeto foi a de trazer educação, cultura e esporte para regiões periféricas da cidade, garantindo, por meio de arquitetura adequada dos prédios e contratação de pessoal especializado, a consolidação do direito à cidadania para os(as) moradores(as) dessas regiões. Para Silva (2019), os CEUs têm representado a concretização de uma concepção de educação básica integral em sentido pleno, atendendo boa parte das necessidades físicas, psicológicas e sociais de crianças e adolescentes, propiciando seus desenvolvimentos. Isso se tornou possível, entre outros aspectos, pelos espaços físicos criados e mantidos para os CEUs.

Mais recentemente, já na segunda década deste século, têm se destacado algumas experiências que tentam associar o fortalecimento da escola pública ao desenvolvimento comunitário de seu entorno. Destacam-se nessa linha os atuais Programas de Ensino Integral dos estados de Pernambuco e de São Paulo, tendo sido o primeiro a inspiração para ao segundo. Os pressupostos dos dois programas são o exercício da cidadania e do protagonismo juvenil (SILVA; DA SILVA, 2016; SÃO PAULO, 2014). Há que se notar que, no programa de São Paulo, não tem havido construção de novos prédios para a implantação da educação integral, no máximo algumas alterações essenciais para seu funcionamento, mas o número de escolas que têm aderido ao programa cresceu substancialmente nos últimos dois anos.

\section{CONSIDERAÇÕES FINAIS}

Este ensaio focalizou a educação integral, tendo como objetivo analisá-la em uma perspectiva histórica, para compreender algumas de suas diferentes concepções. Foi possível, por meio dessa análise, responder à questão orientadora do texto, relativa à identificação de concepções e suas influências em projetos e experiências de educação integral no Brasil.

A tese defendida foi a de que essas concepções vêm sendo elaboradas e reelaboradas historicamente, com base em diferentes projetos de sociedade, com significativa influência de 
fatores econômicos e políticos. Em comum, as diferentes concepções de educação integral analisadas têm a ideia de que à integralidade do ser humano deve corresponder uma educação integral, que vá além dos aspectos físicos e intelectuais de crianças e jovens, contemplando dimensões éticas, estéticas, políticas, afetivas e sociais.

Tendo sua origem na Grécia Antiga, a ideia de uma educação integral tem servido ora como mais uma forma de reforço às estruturas econômicas e sociais vigentes, ora como uma possibilidade de emancipação social por meio da educação escolar. Destaca-se em um largo espectro entre essas duas posições, o ideário liberal, que tem atribuído à educação papel central no desenvolvimento das nações, princípio que parece ser relativamente consensual nos atuais projetos de educação integral vigentes.

Das diversas experiências de educação integral em nosso país, algumas foram mais bem sucedidas e/ou duradouras que outras. Constantes nelas têm sido a preponderância de fatores políticos e de financiamento em detrimento de aspectos pedagógicos e sociais. Nesse ponto, há que se destacar as exceções, tais como o Centro Educacional Carneiro Ribeiro e os Centros Integrados de Educação Pública que foram marcos para a consolidação de uma concepção de educação integral humanizadora, demonstrando a capacidade de inovação de nossos educadores.

Assim, o tema da educação integral mantém-se relevante na atualidade e é uma meta educacional de estados e municípios. Se foi possível estudar como as suas diversas concepções remetem às diferentes visões de sociedade, logo, há que se ter um olhar crítico para essa pluralidade de proposições. Não podemos nos enganar que em tempos em que a lógica do mercado é uma força hegemônica, projetos governamentais de educação integral sejam concebidos e implementados fora ou à parte dela. Nessa lógica, a educação básica é concebida dentro do ideário neoliberal e neoconservador, que serve ao mesmo tempo à manutenção do status quo e à formação de trabalhadores flexíveis, aptos a mudar de área de atuação e a adquirir novas habilidades e competências de acordo com as demandas do mercado e, principalmente, conformados com a falta de vínculos empregatícios garantidores de alguma estabilidade social.

Finalmente, concluímos que o processo histórico desencadeado pela primeira Revolução Industrial até a globalização atual tem modificado as relações entre o homem e o trabalho. Essas mudanças têm sido potencializadas pelas novas formas de comunicação, tecnologias de informação e inteligência artificial. Evidentemente, a escola, instituição formadora por excelência das novas 
gerações, não poderia ficar à parte desse processo. Nesse contexto, tornou-se importante perceber como a educação integral, como um projeto de escolarização, pode contribuir para uma formação humana histórica e planetária, na perspectiva da justiça social e da democracia.

\section{REFERÊNCIAS}

BALDANÇA, Mary Lúcia Medeiros; MIGUEL, Maria Elisabeth Blanck. Breve ensaio sobre a origem dos conceitos de educação integral e educação de tempo integral. In: XI CONGRESSO NACIONAL DE EDUCAÇÃO - EDUCERE, 2015, Anais...Curitiba: PUCPR, 2015, p. 5203-5217. Disponível em: https://educere.bruc.com.br/arquivo/pdf2015/15961_7488.pdf. Acesso em: 3 dez. 2020.

BARROSO, João. O Estado, a educação e a regulação das políticas públicas. Educação e Sociedade, Campinas, vol. 26, n. 92, p. 725-751, 2005.

BERNADO, Elisangela da Silva. Educação em tempo integral: alguns desafios para a gestão escolar. Revista Ibero-Americana de Estudos em Educação, Araraquara, v. 15, n. 1, p. 79-94, jan./mar. 2020.

BOMENY, Helena. A escola no Brasil de Darcy Ribeiro. Em Aberto, v. 21, n. 80, p. 109-120. 2009.

BONATO, Nailda Marinho da Costa; COELHO, Lígia Martha Coimbra da Costa; MENEZES, Janaína Specht da Silva. Educação integral, ensino integral e tempo no pensamento de Rui Barbosa.

Revista HISTEDBR On-line, v. 11, n. 44, p. 275-292, 2011.

BRASIL. Constituição (1988). 36. ed. Brasília, DF: Câmara dos Deputados, 2012. 103 p. (Textos básicos; 70).

CAIUBY, Bianca Barrochelo. Educação de tempo integral: entre entraves e possibilidades. Dissertação de mestrado. 2015. 129 f. Dissertação (Mestrado em Educação). Universidade de Sorocaba, Sorocaba, 2015.

CAVALIERE, Ana Maria. Escolas de tempo integral versus alunos em tempo integral. Em aberto, v. 21, n. 80, p. 51-63, 2009.

CAVALIERE, Ana Maria. Anísio Teixeira e a educação integral. Paidéia (Ribeirão Preto), v. 20, n. 46, p. 249-259, 2010a.

CAVALIERE, Ana Maria. Educação Integral. In: OLIVEIRA, D.A.; DUARTE, A.M.C.; VIEIRA, L.M.F. (Orgs.). Dicionário de Trabalho, Profissão e Condição Docente. Belo Horizonte: Faculdade de Educação - Universidade Federal de Minas Gerais, 2010b.

COELHO, Lígia Martha Coimbra da Costa. Educação integral: concepções e práticas na educação fundamental. In: Reunião anual da associação nacional de pós-graduação e pesquisa em educação-Anped, Anais...2004, v. 27, p. 01-19. Disponível em:

https://anped.org.br/sites/default/files/t137.pdf. Acesso em: 3 dez. 2020.

COELHO, Lígia Martha Coimbra da Costa. Educação Integral e Integralismo: fontes impressas e história(s). Acervo, Rio de Janeiro, v. 18, no 1-2, p. 83-94, 2005. 
COELHO, Lígia Martha Coimbra da Costa. História(s) da educação integral. Em Aberto, Brasília, DF, v. 22, n. 80, p. 83-96, 2009.

COELHO, Lígia Martha Coimbra da Costa; MARQUES, Luciana Pacheco; BRANCO, Verônica. Políticas públicas municipais de educação integral e $(\mathrm{m})$ tempo ampliado: quando a escola faz a diferença. Ensaio: Avaliação e Políticas Públicas em Educação, v. 22, n. 83, p. 355-377, 2014.

DIAS, Kelly Tavares. Escola em tempo integral, educação integral e currículo: um estudo de caso em uma escola estadual em Belo Horizonte. 2015, 233 f. Dissertação (Mestrado em Educação). Pontifícia Universidade Católica de Minas Gerais, Belo Horizonte, 2015.

FIGUEIREDO, Jacqueline de Sousa Batista. A Educação em tempo integral no contexto das políticas públicas brasileiras. In: IV Congresso Ibero-Americano de Política e Administração da Educação ANPAE. Anais...Porto, Portugal, 2014. p. 1-15. Disponível em: https://anpae.org.br/IBERO_AMERICANO_IV/GT5/GT5_Comunicacao/JacquelineDeSousaBatistaFi gueiredo_GT5_integral.pdf. Acesso em: 3 dez. 2020.

FIGLIOLINO, Simone Aparecida Preciozo. Centro Educacional Unificado (CEU): concepções sobre uma experiência. 2014. 194 f. Dissertação (Mestrado em Educação) - Pontifícia Universidade Católica de São Paulo, São Paulo, 2014.

FREIRE, Paulo. Pedagogia da autonomia: saberes necessários à prática educativa. São Paulo: Paz e Terra, 2002.

GALLO, Sílvio. Anarquismo e educação: os desafios para uma pedagogia libertária hoje. Política \& Trabalho - Revista de Ciências Sociais, n. 36, p.169-186, abril de 2012.

JACOMELI, Mara Regina Martins; BARÃO, Gilcilene de Oliveira Damasceno; GONÇALVES, Leandro Sartori. Educação integral do homem e a política educacional brasileira: limites e contradições.

Revista HISTEDBR On-line, v. 17, p. 842-860, 2017.

GIOVANNI, Geraldo; SOUZA, Aparecida Neri de. Criança na escola? Programa de Formação Integral da Criança. Educação e Sociedade, Campinas, v. 20, n. 67, p. 70-111, 1999.

MARIANA, Fernando Bomfim. Educação integral: construção histórica e perspectivas contemporâneas. In: 25으 Simpósio Nacional de Política e Administração da Educação - ANPAE. Anais...São Paulo, 2011, p. 1-13. Disponível em:

https://www.anpae.org.br/simposio2011/cdrom2011/PDFs/trabalhosCompletos/comunicacoesRe latos/0191.pdf. Acesso em: 3 dez. 2020.

MARTINS, Alice Fátima. Escolas-Parque: legado do educador Anísio Teixeira, patrimônio da educação brasileira. Anísio Teixeira na direção do INEP: programa para reconstrução da nação brasileira (1952-1964). Brasília: Instituto Nacional de Estudos e Pesquisas Educacionais Anísio Teixeira, p. 147-158, 2006.

MONTEIRO, Ana Maria. Ciep-escola de formação de professores. Em Aberto, Brasília, v. 22, n. 80, p. 35-49, 2009.

NUNES, Clarice. Centro Educacional Carneiro Ribeiro: concepção e realização de uma experiência de educação integral no Brasil. Em Aberto, Brasília, v. 22, n. 80, p. 121-134, 2009. 
PARO, Vitor Henrique; FERRETTI, Celso João; VIANNA, Cláudia Pereira; SOUZA, Denise Trento Rebello. Escola pública de tempo integral: universalização do ensino e problemas sociais.

Cadernos de Pesquisa, São Paulo, n. 65, p. 11-20, 1988.

SÃO PAULO (Estado). Secretaria de Educação. Diretrizes do programa ensino integral: caderno no gestor. São Paulo: Secretaria da Educação, 2014. Disponível em:

http://www.educacao.sp.gov.br/a2sitebox/arquivos/documentos/342.pdf. Acesso em: 22 abril 2020.

SILVA, Bruno Adriano Rodrigues. Diferenças entre as perspectivas de educação integral em Anísio Teixeira e no programa Mais Educação. Revista HISTEDBR On-line, v. 15, n. 61, p. 202-218, 2015. SILVA, Katharine Nínive Pinto; DA SILVA, Jamerson Antonio de Almeida. Política de Avaliação e Programa de Educação Integral no Ensino Médio da Rede Estadual de Pernambuco: os limites da centralidade da avaliação nas políticas educacionais. Práxis Educativa, v. 11, n. 3, p. 736-756, 2016.

SILVA, Vagnum Dias. Ações formativas voltadas aos(às) diretores(as) de escolas públicas de educação básica no governo Haddad (2013-2016). 2019. 124p. Dissertação (Mestrado em Educação) - Universidade Federal de São Carlos, São Carlos, 2019.

SILVA, Yrlla Ribeiro de Oliveira Carneiro da. A construção dos CIEPS e da escolarização em tempo integral através da formação continuada em serviço: memórias de professores. 2009. 229 p. Tese (doutorado) - Universidade Estadual de Campinas, Faculdade de Educação, Campinas, SP.

TEIXEIRA, Anísio. Uma experiência de educação primária integral no Brasil. Revista brasileira de estudos pedagógicos, v. 38, n. 87, p. 21-33, 1962.

\section{SOBRE OS AUTORES}

\section{Marcelo Oda Yamazato}

Engenheiro de Produção formado pela USP de São Carlos/SP. Mestrando do Programa de PósGraduação em Educação da Universidade Federal de São Carlos - Brasil. Membro do DEFORGES Grupo de Estudos e Pesquisas em Organização Escolar: Democracia, Direitos Humanos e Formação de Gestores.

E-mail marcelo.yamazato@estudante.ufscar.br

ORCID: https://orcid.org/0000-0001-5807-2064

\section{Renata Maria Moschen Nascente}

Doutora em Educação Escolar pela UNESP de Araraquara/SP; Professora Adjunta do Departamento de Educação da Universidade Federal de São Carlos - Brasil e do Programa de Pós-Graduação em Educação da mesma universidade; líder do DEFORGES - Grupo de Estudos e Pesquisas em Organização Escolar: Democracia, Direitos Humanos e Formação de Gestores.

E-mail: renatanascente@ufscar.br

ORCID: https://orcid.org/0000-0001-9395-3166 
Recebido em: 29/04/2020 Aprovado em: 03/12/2020 Publicado em: 11/12/2020 